\title{
Die Algemene Sinode van 2007 en die gereformeerde identiteit van die NG Kerk
}

NGTT DEEL 55, NO 1, 2014

\section{Strauss, PJ}

Universiteit van die Vrystaat

\section{ABSTRACT \\ The General Synod of 2007 and the reformed identity of the Dutch Reformed Church.}

Apparent dissension on core ecclesiastical issues prompted the General Synod of the Dutch Reformed Church of 2007 to take decisions on the reformed identity of this church. A study by one of its commissions on the subject was accepted. In this study, matters such as salvation through grace, faith, Scripture and Christ alone (the so-called 4 solas); the importance of the work of the Holy Spirit, the content of the reformed confessions and a distinction between church and kingdom, are explained.

The Synod also accepted that the solas should be reinterpreted in each period of time. Church unity does not imply that members should think or behave in the same way in all facets church life. 


\section{INLEIDING}

In sy verslag aan die Algemene Sinode van 2007 van die Nederduitse Gereformeerde Kerk (NGK) wys sy Taakspan/Kommissie vir Leer en Aktuele Sake op die besef onder gemeentelede dat NG-dominees oor sake soos die rol van die vrou in die samelewing, homoseksualiteit, aborsie, saamwoon, ewolusie en die model van gemeentewees "nie meer so seker is nie en in elke geval nie meer eenstemmig is nie" (NGK 2004A:130). Hy bevestig sy stelling egter nie met 'n verantwoordbare opname nie. Die blote bestaan van 'n verslag van dieselfde kommissie of taakspan aan die Algemene Sinode van 1998 oor die wyse waarop die NG Kerk sy geloofsbelydenisse aanvaar, skep die moontlikheid dat verskille oor die saak tot hierdie verslag aan die Algemene Sinode van 2007 aanleiding kon gegee het (NGK 1998A:60-62)1․ In sy finale voorlegging aan die Algemene Sinode van 2004 praat die parallelle sessie oor Leer en Aktuele Sake wel van 'n "ingrypende meningsverskil in die NG Kerk" oor die gesag, inhoud en verstaan van die gereformeerde belydenis en spiritualiteit (NGK 2004H:353).

Ek besit 'n harde kopie (getikte voorstel) van 'n "amendement" van dr Lourens Erasmus en ds Lectus Steenkamp by die Algemene Sinode van 2004 wat hierdie presiese woorde gebruik. Die amendement word gestel op 'n voorstel van die Kommissie/Taakspan vir Leer en Aktuele van 2004 waarin die saak voorkom maar die woorde nie gebruik word nie (NGK 2004H:303). Die parallelle sessie op die Leer en Aktuele Sakeverslag neem die bewoording in sy voorlegging aan die Sinode waarskynlik by hierdie twee here oor. Weer is die "ingrypende meningsverskil" gegrond op hulle persoonlike waarnemings en nie 'n wetenskaplike opname nie.

Hoe dit ook al sy, 'n "ingrypende meningsverskil" in 2004 oor kernsake soos die gereformeerde belydenisse van die NG Kerk, verhoog die nodigheid van besluite by dié Algemene Sinode oor die gereformeerde identiteit van die NG Kerk. 'n Geskiedenis van die NG Kerk op algemene sinodale vlak wys hierdie verskil as 'n fenomeen in veral die $21^{\text {ste }}$ eeu - dus na 2000 - uit (Strauss 2013:69,148) 'n Skynbaar groeiende fenomeen wat nie noodwendig met 'n enkele studiestuk en die daaruit vloeiende besluite uit die weg geruim sou word nie.

Die bestaan van meningsverskille oor belydeniskwessies kom in Mei 2005 andermaal na die oppervlakte toe die Moderamen van die Algemene Sinode (ASM) hom genoodsaak ag om op berigte oor 'n moontlike kerkskeuring te reageer.

1 Onder gereformeerde kerkregtelikes is daar'n breë eenstemmigheid dat die belydenisse van die kerk die akkoord van kerklike gemeenskap is, Smit 1984:64. 
Die berigte spruit uit 'n rubriek en opmerkings van Erasmus - die destydse voorsitter van die Vrystaatse Moderamen - in 'n Vrystaatse oggendblad. Die gebeure loop uit op 'n klag teen Erasmus op 28 Junie 2005. 'n Klag wat eventueel by die Vrystaatse Sinode in Oktober 2005 bygelê word (NGK in die OVS 2005:429).

In sy persverklaring wys die ASM daarop dat hy gesprekke in die NG Kerk oor sy gereformeerde identiteit, die rol van sy belydenisskrifte asook Skrifgesag en -hantering nog altyd aangemoedig het. Hy is egter verontrus deur die uitsprake van kerkskeuring. Die ASM en baie NGK-lidmate verwelkom gesprek oor hierdie sake, maar "soek" nie skeuring nie. Gebrekkige inligting oor die wyer debat en die NG Kerk se (amptelike) standpunte skep 'n probleem (NGK 2007A:10).

In sy verslag oor die gereformeerde identiteit van die NG Kerk aan die Algemene Sinode van 2007 meld die takspan vir Leer Aktuele Sake dat hy dit in opdrag van die Algemene Sinode van 2004 doen. Die opdrag behels 'n "inklusiewe" ondersoek waarby die insette van kerkrade, ringe en sinodes asook studiegroepe na aanleiding van beskrywingspunte wat ontvang word, betrek word. Die opdrag is toegespits op die gereformeerde belydenis en spiritualiteit van die NG Kerk, maar die taakspan oordeel dat hy dit breër moet rig naamlik op die aard van die gereformeerdwees van die "lidmate"2 van die NG Kerk. Die verslag moet die werklikheid maar ook die ideaal waarom dit hier gaan, omskryf (NGK 2007A:11).

Verder oordeel die taakspan dat daar 'n diversiteit in oortuigings in die NG Kerk groei waar alles nie oral dieselfde is nie. Die eenheid van die NG Kerk is nie 'n eenvormigheid in alles nie, maar 'n gemeenskaplike kern te midde van 'n diversiteit. Die Algemene Sinode moet dus helderheid kry oor die kernidentiteit of saambindende kern van die kerk van waaruit sy diversiteit as rykdom gevier kan word.

Die NG Kerk kom uit die Protestantse tradisie waarin die Bybel normatief en sentraal staan en aanvaarde belydenisskrifte normatief is. As 'n gereformeerde kerk spruit die NG Kerk uit die 16e eeuse Protestantse Europa van Luther en Calvyn. Die boodskap van die Christelike geloof moet egter telkens in eietydse terme vertaal word. Die gereformeerde vaders het hierin stemreg of inspraak, maar nie 'n vetoreg nie (NGK 2007A:11-12).

Die dogmatikus Dirkie Smit sluit by hierdie gedagte aan. Hy verwys na die karakter van gereformeerdwees en vervolg:

2 Die NG Kerk het natuurlik nie lidmate nie. Hulle is lidmate van die gemeentes van die NG Kerkverband, kyk voetnoot 3. 
...Reformed churches live from their understanding of the gospel, of their understanding of the message of the Scriptures, but this gospel is to be heard anew, again and again, in ever-changing socio-historical circumstances. For the Reformed vision, this gospel is a formative and transformative power, it calls for embodiment in social and concrete forms... both in church and in society... this embodiment is never completed... (but an) ongoing discernment of the claims of the gospel and the concrete forms it should take... the church... (is) called to a critique of destructive powers... (in) the church itself, but also in social and public life(2009:443).

Vir Smit is die gereformeerde kerke se hantering van die boodskap of die implikasies van die Bybel vir kerk en samelewing 'n uitstaande kenmerk van gereformeerdwees: een van die karakteronderskeidings tussen "Calvinist" en "Lutheran views" (2009:423).

Teen hierdie agtergrond moet die inhoud van die gereformeerde identiteit van die NG Kerk na aanleiding van die reaksie van die Algemene Sinode van 2007 op die verslag van sy taakspan vir Leer en Aktuele Sake, verstaan word.

Twee kwalifiserings is op hierdie punt nodig.

Die eerste is dat die omskrywing van die gereformeerde identiteit van die NG Kerk in hierdie verslag eerder kerklik as akademies moet wees. Dit gaan hier om sinodebesluite in die kerk as 'n Christelike geloofsverband wat deur nie-teologiese lidmate verstaan en aanvaar word. Sinodebesluite wat hulle geloofsoortuigings vanuit hulle eie verstaan van sake - vertolk. Die taakspan self noem dit' $n$ "inklusiewe" ondersoek waarby kerkrade, ringe, sinodes en studiegroepe van gelowiges of "gewone" lidmate ook betrek word (NGK 2007A:11).

Die tweede kwalifisering is dat dit hier eerder om positiewe stellings wat jou kerklike en geloofskarakter verwoord, as 'n volledige akademiese relaas van ondermeer verskille met ander standpunte of afwykings, moet gaan. Dit moet om verduidelikende tetiese stellings van gereformeerdwees gaan.

\section{DIE SOLA'S}

Ter inleiding wys Leer en Aktuele Sake daarop (NGK 2007A:13-17) dat die eerste woord oor die identiteit van die NG Kerk nie "gereformeerd" kan wees nie. So iets is juis nie gereformeerd nie. 
Volgens die taakspan is die lidmate van die gemeentes van NG Kerk ("ons") in die eerste plek nie gereformeerdes nie, maar Christene. Mense wat aan God behoort. Die Latynse uitdrukking coram Deo is 'n kernagtige weergawe waaroor dit eintlik vir gereformeerdes gaan, naamlik'n lewe voor of gerig op God.

Simbole van gereformeerde kerke gee aan hierdie opvatting uitdrukking. Die vertikale kerktoring, die sakramente van die doop en die nagmaal, die kruis en die oop Bybel op die kansel "gaan oor God" (De Klerk 1982:129-130). Alle formulerings in verband met 'n gereformeerde kerklike identiteit "wentel" hierom heen.

Hierdie opmerkings van die taakspan is in die kol. Die kern is die stelling dat 'n lewe voor God die kern van gereformeerdwees is. Met hierdie stelling voorkom die taakspan die indruk dat hy Christenwees en gereformeerdwees teenoor mekaar stel. Meer nog, hy gee ook uitdrukking aan 'n gereformeerde oortuiging dat dit om die volle lewe as 'n offer aan God gaan. Dit word later weer bespreek.

Volgens die taakspan is die bekende "solas" van die Reformasie 'n bondige manier om die kernsake van gereformeerdwees uit te druk. Dit gaan oor die sola scriptura (deur die Woord alleen) wat destyds veral teen die beweerde gesagvolle Roomse kerklike tradisie van leeruitsprake en beheer oor Skrifuitleg gemik was. 'n Tradisie wat hierdie uitsprake as gelyk met en ewe gesagvol as die Bybel gestel en die leerstuk oor die verlossing van die mens deur die genade (sola gratia) en die Woord alleen verduister het. Vir die Reformasie kon natuurlike kennis van God nie opweeg teen die Skrifopenbaring van God nie. Daar is geen "natuurlike kennis" waardeur'n mens gered word nie. Teenoor die bemiddeling van die Roomse priester het die Reformasie solus Christus (Christus alleen) gestel. Dit is alleen moontlik as die boodskap van Christus as Verlosser deur die sola fide (geloof alleen) gevat word. Goeie werke laat jou nie kwalifiseer vir God se genade en verlossing nie (Pont 1999:53).

Die taakspan plaas hierdie vier solas onder 'n vyfde: soli Deo Gloria. Vir hulle is dit die dak waaronder die ander vier inpas. Die solas was destyds handig teen die RoomsKatolieke wanpraktyke van die 16e eeu, maar hulle glo dat dit telkens "kontekstueel" hersien moet word. Hierdie begrip gee volgens die taakspan gestalte aan die idee dat

3 Kleynhans wys daarop dat die gemeentes die plek is waar die gelowiges bymekaar kom of waarby hulle inskakel, 1982:80. Die is kerk is nie 'n soort vrywillige vereniging met lede waarvan die gemeentes die ondergeskikte takke is nie. 'n Kerkverband soos die NG Kerk bestaan uit gemeentes as volledige kerke wat op hulle beurt uit lidmate bestaan, Keet 1963:42vv. Op sy beurt wys die taakspan daarop dat die gemeente in gereformeerde taal volledig kerk is, maar nie die hele kerk nie, NGK 2007A:14. Hierdie uitdrukking is van Heyns 1977:169-170. 
'n gereformeerde kerk gedurig reformeer. 'n Verstokte gereformeerde kerk noem hulle 'n innerlike teenstrydigheid.

Twee kritiese waarnemings tref by hierdie formulerings.

Die eerste is die byna onafmanier waarop die solas omskryf word. Om 'n kern kwessie te noem: hoe moet 'n sola "kontekstueel" hersien word? Of is dit die toepassing van die bekende (ou) vyf solas in 'n nuwe konteks wat hersien moet word? Is die solas konstantes of is hulle "kontekstueel" of konteksbepaald en moet hulle dáárom telkens hersien word? Is die idee agter elke sola konstant, maar die formulering daarvan oop vir hersiening?

Beteken hierdie kontekstuele hersiening in nuwe tye dat die solas hulle solakartakter kan verloor? Watter deel van die bondige formulering van die solas is konteksbepaald? Gee die solas meer as 'n konstante kern, of is dit self die konstante kern? Indien die solas as solas hersien moet word, is die gereformeerde voorvaders uit die hoek van die behoud van voortgaande reformasie in die kerk en die samelewing nie dalk geregtig op 'n vetoreg nie? Dit gaan hier immers om reformasie gemeet aan die solas as konstantes.

Tweedens stel die taakspan die sola gratia teenoor natuurlike Godskennis as die middel tot verlossing, terwyl dit in die literatuur eerder teenoor die doen van "verdienstelike" goeie werke of werkheiligheid gestel word (Schulze 1978:133; De Jong 1987:161; Jonker 1994:32-33). Natuurlik kan natuurlike godskennis as 'n "goeie" werk kwalifiseer. Dit was egter nie die kern van die historiese konteks van die sola gratia en sola fide in die tyd van die Reformasie nie. In 1520 - net nadat sy bekende 95 stellinge teen die kerkdeur in Wittenberg wat die Reformasie sneller - publiseer die Hervormer Martin Luther juis 'n boekie Oor goeie werke. Dit kom binne die raamwerk van sy stryd teen die Roomse aflate en bieg en die Liepzig-debat teen Johannes Eck (Kuiper 1995:157-181).

Daarby waag die taakspan hulle nie aan wat die lidmate van NGK-gemeentes van die solas maak nie. Ten spyte van die feit dat dit een van hulle verklaarde doelstellings is. Hulle gee ook nie voorbeelde van hulle eie "kontekstuele" hersiening van die solas nie.

\section{DIE HEILIGE GEES}

Met sy stelling dat Calvyn baie "klem" op die werk van die Heilige Gees lê, bevind die taakspan hom in goeie geselskap. Jonker (1994:38) en Van Wyk (1983:5) gebruik die uitdrukking dat Calvyn "die teoloog van die Heilige Gees" genoem kan word, met groot instemming. Vir beide is die werk van die Gees onlosmaaklik van die 
van die Vader en die Seun. Hulle noem Hom die Gees van God en Christus wat die verlossing in ons bewerk.

Die taakspan beskryf die klem op die werk van die Heilige Gees as tiperend van die gereformeerde teologie. Die lewe voor God is 'n lewe in die kragveld van die Gees. Die opkoms van die Pentekostalisme in die laat twintigste eeu met hulle opvattinge oor die persoon en werk van die Heilige Gees vra 'n duideliker onderskeid op hierdie punt tussen hulle en die gereformeerdes. Tipies van die NG Kerk vandag erken die taakspan egter dat gereformeerdes "veel" van dié rigting kan leer: hulle sterk bewussyn van God se krag, gees van aanbidding en ywer vir getuienis.

Wat die taakspan nalaat om te sê is dat hierdie aanbidding en getuienis in 'n konteks en met 'n inhoud plaasvind wat vreemd is aan getoetsde gereformeerde uitgangspunte (Strauss 1995:13-36). Die taakspan noem ingrypende verskille in Skrifuitleg en -aanpak met die tradisionele Pentekostalisme óók net "klemverskille". Die voorbeelde wat hulle ophaal, dui egter op meer as net klemverskille.

Die takkspan wys op die noue verbintenis by gereformeerdes tussen die Woord en Gees van God. By gereformeerdes is daar "minder ruimte" vir bonatuurlike visioene en "vrye profesie" as by die Pentekostalisme. Gereformeerdes handhaaf'n soberder nadenke oor die Woord in elke nuwe konteks. Oor die gawes van die Gees verwerp hulle die uitlig van ongewone tale of klanke (spreek in tale) as dié teken van vervulling met die Gees. Hulle beklemtoon alle gawes wat die gemeente opbou en die liefde as die "allerbeste gawe".

Oor die doop met die Heilige Gees aanvaar gereformeerdes die Bybelse opdrag dat ons heiligheid moet najaag, maar ook dat niemand kan sê dat Jesus die Christus is sonder die Heilige Gees nie (Van't Spijker 1991:121). Daar is nie mense met "meer" en "minder" van die Gees nie, omdat die Gees 'n persoon en ondeelbaar is. Die doping met die Gees as 'n tweede of derde ervaring na bekering word afgewys (Strauss 1995:13-17). Met die gereformeerde tradisie van die mens as "gelyktydig sondaar en geregverdig" (afkomstig van Luther se simul justus ac peccator, De Jong 1987:170) is daar natuurlik verskille in gehoorsaamheid en 'n wandel in die Gees. Mense kan uit ongehoorsaamheid die Gees weerstaan of uitblus.

Die taakspan behou die gereformeerde kern van sy betoog wat hy bondig en duidelik stel. Tog klink hy op sekere punte nog onaf.

As 'n teoloog van die Gees en die Woord van God as 'n onlosmaaklike tweeling, as 'n inisieerder van die uitdrukking "deur Woord en Gees", sou Calvyn onmiddellik by die taakspan wou weet of enige werklike openbaring van God - natuurlik of bonatuurlik - los van die binding en kontrole van die Woord kan bestaan? Bestaan die vrye profesie as 'n werklike vrye profesie nie eers in gebondenheid aan die Woord 
nie? Of is die enigste regstelling op die Pentekostalisme hierin net dat dit vaagweg "minder" moet wees?

Is minder openbarings en profesieë net omdat hulle "minder" is, gereformeerd of "meer" gereformeerd?

Die nalatige omruiling van Luther se justus en peccator as'n bekende dogmahistoriese sêding skep die vraag van hoe naby aan die "bronne" die taakspan in sy verslag beweeg het. Die verslag gee geen Skrifgebaseerde uiteensetting van die doping óf vervulling met die Gees nie, terwyl 'n verduideliking op hierdie punt noodsaaklik is. Al twee begrippe kan met'n positiewe Bybelse inhoud gevul word, terwyl die debat oor die doping met die Gees oor veel meer as heiliging - dit wat die verslag impliseer - gaan (Strauss 1995:13-22).

\section{KERK EN KONINKRYK}

Die taakspan wys met reg daarop dat die kerk 'n belangrike plek inneem in die lewe van gereformeerde gelowiges. Dit is een van die kenmerke van die gereformeerde kerkbegrip dat die geloof nie "volledig" opgaan in kerkwees nie. Die koninkryk is groter as die kerk. Die taakspan beskou die kerk as 'n teken van die koninkryk. Lidmate wil nie hulle lewens verkerklik nie, maar ver-Christelik.

Smit beklemtoon dat die gereformeerde Protestantisme verskil met die Lutheranisme oor die implikasies of effek van gehoorsaamheid aan die Woord en wil van God buite die kerk in die res van samelewing. Hierdie vertrekpunt het gelei tot

...far-reaching historical significance, for it decisively affected the political and social evolution of the lands that came under the sway of Calvinistic churchmanship and preaching (2009:423).

Met "geloof" soos hier gebruik deur die taakspan, beoog hulle om die volle Christelike lewe of 'n koninkryksomvattende lewe uit te druk. 'n Lewe wat strukture soos die kerk én ander samelewingstrukture binne die koninkryk insluit. 'n Lewe wat gehoorsaamheid of 'n Christelike lewenstyl op alle terreine vra. Waaroor dit hier duidelik nié gaan nie, is die omskrewe geloof in antwoord 21 van die Heidelbergse Kategismus (NGK 1982:44) of die spreekwoordelike "heilige, algemene Christelike geloof" soos verwoord in die NG Kerk se algemene én gereformeerde belydenisskrifte (Jonker 1994:18-19).

Volgens die taakspan het die kerk sy bestaan aan God te danke. Dit behoort aan die Here wat dit die wêreld instuur. Die kerk is verbind aan die Woord as identiteitsdokument en die viering van die genade van God deur die bediening van 
die sakramente en die handhawing van sy belydenis ${ }^{4}$. In sy struktuur komplementeer twee begrippe mekaar: die gemeente as volledig maar nie die hele kerk nie, en die gemeente met ander gemeentes in kerkverband (Heyns 1977:169-170).

Die vervulling van die ampte en leierskap in die kerk moet gepaardgaan met diens. Die erkenning van die gelykwaardigheid van die ampte sluit hiërargie en heerskappy uit (vgl Kleynhans 1984:1; Strauss 2008:279; Strauss 2010:40). Dit gaan om die heerskappy van die Woord waaraan alles getoets en waarmee alles gekontroleer word en nie van mense nie (Jonker 1965:27).

Die ideaal van die vestiging van God se koninkryk op aarde beteken dat die gelowiges op elke "duimbreedte" van die lewe tekens van die koninkryk of gehoorsaamheid aan die Koning moet oprig (Kuyper 1930:32) ${ }^{5}$. Die lewe voor God (die coram Deo van die lewe) is 'n roeping: van piekniek hou tot preek.

\section{LITURGIE EN BELYDENISSE}

Die takkspan is kort en bondig as hy sy verslag oor die gereformeerde identiteit van die NG Kerk en die liturgie in hierdie gemeentes inlei. "Die liturgie is 'n uitdrukking van hoe 'n kerk die Evangelie verstaan".

Volgens die taakspan is die gereformeerde tradisie'n hoor-tradisie wat 'n groot klem op die lees en uitleg van die Bybel plaas. Daarom is die prediking as kontekstuele Skrifuitleg'n sentrale oomblik in die erediens. Liedere, gebede en getuienisse versterk die rol van die Bybel en die sakramente is die "sigbare Woord". Die belydenisskrifte stem ooreen met die Bybel en behoort "integraal deel van elke erediens te wees". Hoewel die kerke in die gereformeerde tradisie vanuit hulle anti-Roomse oorsprong "effe huiwerig" vir'n oormatige fokus op rituele en simbole is, kan dinge soos kruise, kanselklede en salwing die Woord bevestig en versterk (De Klerk 1982:43, 121-124).

Verantwoorde liturgiese vernuwing soos nuwe liedere in die idioom van die tyd en ander begeleidingsinstrumente as die orrel kan 'n uitvloeisel van die reël semper reformanda wees mits dit nie lei tot die prysgawe van liturgiese middele wat die toets van die tyd deurstaan het nie.

4 'n Uiteensetting van die implikasies van die merktekens of kenmerke van die ware kerk in artikel 29 van die Nederlandse Geloofsbelydenis sou in hierdie geval tot 'n meer afgeronde (volledige) resultaat gelei het. Vir Calvyn se invloed op hierdie artikel van die belydenis, Praamsma sa:264.

5 Die taakspan skryf die woordjie "duimbreedte" aan Willie Jonker toe sonder om enige verwysing te gee. Dit is egter Abraham Kuyper wat dit in die 19e eeu in gereformeerde kringe inburger, Strauss 1993:10. 
Gereformeerdes glo dat die erediens uit 'n paar kernelemente bestaan soos Skriflesing, die wet, skuldbelydenis, genadeverkondiging, voorbidding en lofprysing. Vaste credo's of belydenisse en formuliere is nie dwangbuise nie, maar daar om aan die band met mekaar en die wyer ekumeniese kerk uitdrukking te gee (De Klerk 1982:67-88; Strauss 2013:77).

As die taakspan verwys na die erkende belydenisskrifte van die kerk gebruik hy die besluite van die Algemene Sinode van die NG Kerk van 1998 oor die wyse waarop hierdie kerk sy belydenisskrifte aanvaar. Die NG Kerk se drie algemene belydenisskrifte naamlik die Apostolicum en Belydenisse van Nicea en Athanasius en die Drie Formuliere van Eenheid naamlik die Nederlandse Geloofsbelydenis, Heidelbergse Kategismus en die Dordtse Leerreëls is gesagvol in die gereformeerde geloofsoortuiging of die saak wat hulle (quia) volgens die Skrif bely. Hierdie oortuiging sluit nie die wysiging of aanvulling van hierdie belydenisse uit nie. So iets moet egter op 'n kerkordelike wyse geskied.

Die belydenisskrifte is historiese dokumente wat die tekens van hulle tyd en van hulle menslike ontstaansgeskiedenis vertoon. Hulle is egter gesagvol in die kernwaarhede van die Evangelie of die Christelike geloof wat hulle bely (NGK 1998A:60-62; Strauss 2013:50-52).

'n Kerk in die gereformeerde tradisie wat tot dieselfde slotsom as die NG Kerk gekom het en volle kerklike verhoudinge met die NG Kerk handhaaf, is die Christian Reformed Church of North America. Vir hierdie kerk beteken instemming met die belydenisskrifte instemming met "those doctrines which are confessed" omdat (quia) dit in die Bybel geleer word (Engelhard en Hofman 2001:51).

Die taakspan maak gewag van 'n sombere, sobere mensbeeld wat gevoed sou word uit die gereformeerde belydenisskrifte met hulle klem op sonde en genade.

Die kern van die gereformeerde mensbeeld hou egter verband met die antwoord op vraag 1 van die Heidelbergse Kategismus: Wat is jou enigste troos in lewe en in sterwe?

Die antwoord van die taakspan: dat ons nie meer aan onsself behoort nie, maar aan God. Dat ons aan ons getroue Verlosser en Saligmaker Jesus Christus behoort.... (NGK 1982:39) 'n Antwoord wat'n verantwoordelikheid en omvattende dissipelskap impliseer. Dit spruit immers uit 'n verbondsverhouding waarin die Here belowe om ons God te wees maar eis dat ons sy gehoorsame kinders sal wees. Elke verbond waarby die Here betrokke is, bevat beloftes en eise (Calvyn sa:320) . 


\section{BALANS}

As hierdie verslag met sy omskrywing van die gereformeerde identiteit van die NG Kerk deurgewerk word, moet die vraag gevra word: het dit sy oogmerke soos deur homself aan die orde gestel, bereik? Gaan dit hier om die gereformeerdwees van "gewone" lidmate en ampsdraers, gemeente-aktiwiteite en vergaderings, om die NG Kerk in sy geheel? En is die "ideaal" van 'n gereformeerde identiteit behoorlik omlyn?

Gaan dit hier inderdaad om die sogenaamde "werklikheid" én die ideaal? Die bewoording van sy taak soos deur die taakspan self gekies.

Wat meer is, is hier 'n deeglike ondersoek na 'n groeiende diversiteit te midde van 'n saambindende kern waarvan aan die begin melding gemaak is? Het die verslag ook die "ingrypende meningsverskil" hanteer wat 'n groot rol by die gee van die opdrag gespeel het? 'n Meningsverskil wat ook in belydenisverskille teenwoordig kan wees?

Die feit dat die verslag uit 'n inklusiewe ondersoek waarby lidmate oor 'n breë spektrum betrek word, moes spruit, speel in op hierdie doel van die ondersoek. Die verslag self gee inhoudelik egter geen aanduiding van watter stellings van watter groep af kom nie.

Oor sy werkswyse meld hy dat hy van publikasies, die bydraes van teoloë en van sinodale studiestukke gebruik gemaak het. Die konsep- of werksdokument is met 'n groep lidmate wat in vyf sessies gesien is, deurgewerk, terwyl die Algemene Diensgroep vir Gemeente-ontwikkeling ook insette en kommentaar gelewer het.

Kortom, nie-teoloë het eers by die konsep van die verslag bygekom en nie van die begin af nie. Dit laat die vraag ontstaan of die onverwerkte of outentieke bydraes van lidmate in die verslag gehoor word? Die groep lidmate wat wel betrek is: hoeveel is hulle en hoe verspreid in die kerkverband - byvoorbeeld geografies en ouderdomsgewys - is hulle? Was so 'n verspreiding prakties moontlik indien dit oor vyf sessies versprei is?

Is hierdie werkswyse die rede waarom die verslag meer 'n teologiese as 'n gewonelidmaat-inslag vertoon? Waarom daar nie spesifieke verwysings is van wie gegewens kom nie? Selfs die insette van die NG-teoloë kom nie uit 'n wye kring nie. Is dit die rede waarom die geykte "ingrypende meningsverskil" en 'n "groeiende" diversiteit nie in besonderhede behandel word of glad nie aan die bod kom nie? Waarom die paar teoloë én dominees soos - volgens die verslag - geraadpleeg, skynbaar hulle eie stempel op die stuk afgedruk het? 
'n Tweede punt van kritiek - veral in die Suid-Afrikaanse en Afrikakonteks van die NG Kerk - is sekerlik die vraag watter rol die aanvaarde gereformeerde identiteit van die NG Kerk in sy houding oor apartheid voor en na 1986-1990 gespeel het? Watter rol hierdie identiteit in sy aanvaarding van die apartheidkritiese dokumente Kerk en Samelewing-1986 en -1990 gespeel het? In sy besinning oor gereformeerdwees in Suidelike Afrika noem Smit hierdie 'n kernsaak van die NG Kerk se gereformeerde identiteit: hoe gereformeerdes die implikasies van die Woord op die samelewing toepas (2009:218vv).

Hy haal Jonker aan wat dieselfde koppeling doen en dan 'n volgende, hieraan relevante, kwessie opper:

Waar die stryd in die afgelope veertig jaar hoofsaaklik om die deurbreking van die volkskerkkarakter van die NG Kerk gegaan het, sal dit in die volgende dekades waarskynlik... (ondermeer gaan) om die bewaring van die gereformeerde karakter van hierdie kerke en hulle profetiese roeping in die samelewing (1998:220-221).

Hoe breed 'n verslag oor die gereformeerde karakter van die NG Kerk egter kan word, word ook uit die gebruik van die drie merktekens van die ware kerk in die Nederlandse Geloofsbelydenis (artikel 29) duidelik: die suiwere bediening van die Woord en die sakramente en die handhawing van die kerklike tug.

Die belydenisse van die NG Kerk word in die verslag "normatief" genoem. Dit beteken dat die handhawing van sy gereformeerde belydenisskrifte 'n bepalende element is van die gereformeerde identiteit van die NG Kerk. In hierdie geval raak dit die tug in die NG Kerk. Het die NG Kerk'n tuglose kerk geword en is hy so gesien nog gereformeerd?

Die vraag na die effek van die normatiewe belydenisskrifte van die NG Kerk in dié kerk self kan nie sonder 'n afbakening en keuse van temas in 'n sinodale verslag soos hierdie gepeil word nie. Daar is eenvoudig te veel sake in die bestaande belydenisskrifte vir net een so 'n verslag!

Die probleem is egter dat die taakspan dit skynbaar nie eers oorweeg het nie. Anders gestel: as 'n ingrypende meningsverskil om belydeniswaarhede draai, draai die diversiteit van die NG Kerk soos in die verslag genoem, nie ook hierom nie? As belydeniswaarhede afgestem is op die kernwaarhede van die Evangelie (Jonker 1994:6), is "ingrypende" verskille in die NG Kerk nie per definisie juis belydenisverskille of verskille met belydenisimplikasies nie? Kan verskille hieroor nie ook die gereformeerde identiteit van die NG Kerk beïnvloed nie? 
As die gereformeerde belydenisskrifte volgens die taakspan 'n integrale rol in elke erediens moet speel, hoekom figureer dit inhoudelik en eksplisiet nie sterker in dié verslag nie? As dit hier gaan om die gereformeerde belydenisskrifte en die gereformeerde identiteit van die NG Kerk: is dit genoeg om net te vermeld dat eersgenoemde normatief moet inwerk op laasgenoemde? Kan die vier solas byvoorbeeld - eksplisiet gekoppel word aan die Drie Formuliere van Eenheid?

\section{SLOT}

Die verslag van sy Taakspan vir Leer- en Aktuele Sake oor sy gereformeerde identiteit aan die Algemene Sinode van 2007 van die NG Kerk, bring helderheid oor sommige sake, maar laat vrae oor ander aspekte.

Die kwessie van 'n gereformeerde kern wat die NG Kerk bind of bymekaar hou te midde van aksent- en ander verskille, is verhelderend. Ook die stelling dat die solas vir die NG Kerk 'n bondige manier is om die kernsake van sy gereformeerdwees te verwoord, is 'n wins. 'n Gereformeerdwees wat bepalend beïnvloed word deur die belydenisskrifte van die NG Kerk en die genadeverbond van God met die mens. Voeg hierby die verskil wat die taakspan maak tussen die kerk en die koninkryk met die stelling dat hy kies vir 'n verchristeliking en nie 'n verkerkliking van die samelewing nie. Gereformeerdwees word tereg as 'n "hoor"-tradisie en die erediens as 'n uitdrukking van hoe die kerk die Evangelie verstaan, beskryf. Onder soli Deo Gloria bring die taakspan die kern van die gereformeerde tradisie van die NG Kerk tuis.

Daar is egter ook dinge in hierdie verslag wat hinder of onaf is.

Die eerste is die onbeantwoorde vraag of die nie-teologiese lidmate van NGgemeentes as die oorgrootte meerderheid 'n aanduibare rol in die verslag gespeel het. Die tweede vraag is wat met 'n gereelde kontekstuele hersiening van die solas, in sigself kernwaarhede, bedoel word? Die kwessie van die Gees, die Woord, vrye profesie en die Pentekostalisme word vaag en onbevredigend hanteer.

Tog word hiermee'n verteerbare gereformeerde identiteit vir die NG Kerk aangedui.

\section{LITERATUURLYS}

Beeld 2006.

Calvyn, J sa. Institutie IV (Vertaling van A Sizoo), Delft: Meinema.

De Jong OJ 1987. Geschiedenis der kerk. Nijkerk: Callenbach. 
De Klerk, JJ 1982. Liturgiese grondlyne. Kaapstad: NG Kerk-Uitgewers.

Engelhard, DH en Hofman, LJ 2001. Manual of Christian Reformed Church Government. Grand Rapids: CRC Publications.

Heyns, JA 1977. Die kerk. Pretoria: NG Kerkboekhandel.

Jonker, WD 1965. Om die regering van Christus in sy kerk. Pretoria: Unisa.

Jonker, WD 1994. Bevrydende waarheid. Wellington: Hugenote-Uitgewers

Jonker, WD 1998. Selfs die kerk kan verander. Kaapstad: Tafelberg.

Keet, BB 1963. Orde in die kerk. Kaapstad: NG Kerk-Uitgewers.

Kleynhans, EPJ 1982. Gereformeerde Kerkreg I. Pretoria: NG Kerkboekhandel

Kleynhans, EPJ 1984. Gereformeerde Kerkreg II. Pretoria: NG Kerkboekhandel.

Koffeman, LJ 2009. Het goed recht van de kerk. Kampen: Kok.

Kuiper, BK 1995. The church in history. Grand Rapids: CSI Publications.

Kuyper, A 1930. Soevereiniteit in eigen kring. Kampen: JH Kok.

NG Kerk 1982. Die drie formuliere van eenheid en ekumeniese belydenisse.

Wellington: NG Kerk-Uitgewers.

NG Kerk 1998A. Agenda van die Algemene Sinode. Sl:sn.

NG Kerk 2004A. Agenda van die Algemene Sinode. Sl:sn.

NG Kerk 2004H. Handelinge van die Algemene Sinode. Sl:sn.

NG Kerk 2007A. Agenda van die Algemene Sinode. Sl:sn.

NG Kerk 2011. Die Kerkorde. Sl:sn.

NG Kerk in die OVS 1865-1912. Handelinge van die eerste tot die vier en twintigste vergadering. Sl:sn.

NG Kerk in die Oranje-Vrystaat 2005. Handelinge van die sinode. Sl:sn.

Praamsma, L sa. Calvijn. Wageningen: Zomer en Keunings. 
Pont, AD 1999. Die kerkhervorming. Pretoria: Radio Pretoria.

Schulze, LF 1978. Geloof deur die eeue. Pretoria: NG Kerkboekhandel.

Smit, CJ 1984. God se orde vir sy kerk. Pretoria: NG Kerkboekhandel van Transvaal.

Smit, DJ 2009. Essays on being Reformed. Stellenbosch: Sun Media.

Strauss, PJ (red) 1991. Byderwets en gereformeerd. Bloemfontein: Pro Christo.

Strauss, PJ 1993. Op die tweesprong. Bloemfontein: UV.

Strauss, PJ 1995. Die gees werk soos Hy wil... Bloemfontein: VCHO.

Strauss, PJ 2007. Die sinodale verband van die NG Kerk in die Oranje-Vrystaat: enkele tendense by die ontstaan daarvan in 1864-1865. Acta Theologica 27/1:121-133.

Strauss, PJ 2008. Die Kerkorde van die NG Kerk: uitgangspunte ten opsigte van Skrif, belydenis en kerkrode. Acta Theologica 28/2:104-117.

Strauss, PJ 2010. Kerk en orde vandag. Bloemfontein: Sun Media.

Strauss, PJ 2013. Kerkwees in die branding. Die NG Kerk in algemene sinodale verband 1994-2011. Bloemfontein: Sun Media.

Van Wyk, JH 1983. Calvyn oor die Christelike lewe. Pretoria: NG Kerkboekhandel Transvaal.

Van't Spijker, W 1991. Geest, Woord en kerk. Kampen: Kok.

\section{TREFWOORDE}

Gereformeerde identiteit

Alleen die genade, geloof, Skrif en Christus

Calvyn teoloog van die Heilige Gees

Belydenis het gesag in geloof wat bely word

\section{KEY WORDS}

Reformed identity

Only through grace, faith, Scriptures and Christ 
STRAUSS, PJ

Calvin theologian of the Holy Spirit

Creeds have authority in the faith it confess.

\section{KONTAKBESONDERHEDE}

Prof PJ Strauss,

Fakulteit Teologie,

Universiteit van die Vrystaat,

Posbus 339,

Bloemfontein.

9300.

Tel: 051-4012671

Sel: 0825573414

E pos: straussp@ufs.ac.za 